\title{
Incidence of cytogenetic aberrations in two B lineage subpopulations in multiple myeloma patients analyzed by combination of whole-genome profiling and FISH
}

\author{
J. SMETANA ${ }^{1,2, *}$, E. DEMENTYEVA ${ }^{2, *}$, F. KRYUKOV², P. NEMEC ${ }^{1,2}$, H. GRESLIKOVA ${ }^{2}$, R. KUPSKA ${ }^{2}$, A. MIKULASOVA ${ }^{1,2}$, I. IHNATOVA ${ }^{3}$, R. HAJEK ${ }^{2,4,5}$, \\ P. KUGLIK ${ }^{1, *}$
}

${ }^{1}$ Department of Experimental Biology, Faculty of Science, Masaryk University, Brno, Czech Republic; ${ }^{2}$ Babak Myeloma Group, Department of Pathological Physiology, Faculty of Medicine, Masaryk University, Brno, Czech Republic; ${ }^{3}$ Institute of Biostatistics and Analyses, Faculty of Medicine, Masaryk University, Brno, Czech Republic; ${ }^{4}$ Department of Internal Medicine-Hematooncology, University Hospital Brno, Czech Republic; ${ }^{5}$ Department of Clinical Hematology, University hospital Brno, Czech Republic

*Correspondence: kugl@sci.muni.cz

${ }^{*}$ Contributed equally to this work.

\section{Received April 03, 2013 / Accepted May 23, 2013}

\begin{abstract}
Multiple myeloma (MM) is an incurable malignant disease of the terminal developmental stage of B-lymphocytes. While genetic heterogeneity of MM is widely described, little is known about its genetic basis as well as primary damage during plasma cells (PC) development. In this study, we focused on genome-wide screening of DNA copy number changes using oligonucleotide-based array-CGH together with I-FISH of the IgH locus rearrangements in pair samples of bone marrow B-cells (CD19+) and CD138+ PC from newly diagnosed MM patients. The IgH disruption was found in $8.9 \%$ $(4 / 45)$ of CD19+ samples and in 57.8\% (26/45) of CD138+ samples. The genomic profiling using array-CGH identified copy number alterations (CNAs) in $10 \%(2 / 20)$ of CD19+ samples in regions known to be important for MM pathogenesis. In contrast, we found CNAs in 100\% (16/16) of CD138+ samples. Most common chromosomal abnormalities were trisomies of odd-numbered chromosomes $(3,5,7,9,11,15,19$ and 21), gain 1q, gain Xq and monosomy of chromosome 13. We did not find any correlation between incidence of CNAs in CD19+ and CD138+ cells. In conclusion, effective utilization of FISH and array-CGH can identify genetic lesions in premalignant stages leading to better understanding and characterization of MM.
\end{abstract}

Key words: multiple myeloma, CD19+, CD138+, cytogenetics, array-CGH, FISH

Multiple myeloma (MM) is an incurable malignant disease of the terminal developmental stage of B-lymphocytes, which is characterized by recurrent translocations into the immunoglobulin heavy chain locus as well as multiple and complex chromosomal abnormalities acquired in advanced stages of the disease [1]. While incidence and effects on prognosis of genetic lesions in MM are widely accepted and evaluated in malignant plasma cells (PCs), little is known about genetic basis or mechanism of myeloma pathogenesis as well as timing of primary damage during B-cells development [2,3]. The presence of genetic lesions may be caused by de novo mutations but some of them may occur in early developmental stages of PC $[4,5]$. The discovery of (surface) immunoglobulin-positive $\mathrm{B}$-cells expressing the same patient-individual variable region immunoglobulin (Ig) rearrangement as the malignant PC clone - so called clonotypic B-cells - has therefore fuelled speculations about a potential premalignant B cell compartment in MM [6,7].

Several studies have compared genetic lesions in PCs with those in the peripheral B-cell compartment, supporting a model of intraclonal evolution at the PC level [8-11]. However, clear correlation between patterns of chromosomal alterations in B-cells and PCs was not found.

Nowadays, the composition of MM clonogenic population as well as the role of B- lymphocytes in malignant transformation of myeloma clones remains unclear. It was established that some subsets of B-lymphocytes are aneuploid and probably may mediate spread of the malignant clone [12,13]. It was suggested that the malignant clone also includes phenotypically wide range of B-lymphocytes that share the clonotypic immunoglobulin heavy chain $(\mathrm{IgH})$ VDJ gene rearrangement characterizing autologous PCs [14]. Furthermore, it was 
assumed that the MM clone includes also late-stage B-cells and pre-switch B-cells $[15,16]$. While the existence of B-lymphocytes belonging to the myeloma clone is still controversial, there should be evidence of myeloma-specific genetic markers in this population.

Taking all of the above into consideration, we focused our study on genome-wide screening of DNA copy number changes using oligonucleotide-based array-CGH together with I-FISH examination of $\mathrm{IgH}$ locus rearrangement at chromosome $14 \mathrm{q} 32-\mathrm{t}(14 \mathrm{q} 32)$ in pair samples: bone marrow B-cells (CD 19+) and PCs (CD138+) from newly diagnosed MM patients. We anticipate that bone marrow (BM) abnormal B cell subset may have genetic background for primary oncogenic events.

\section{Material and methods}

Patients and sample preparation. A total of $54 \mathrm{MM}$ patients from the University Hospital Brno, Czech Republic were included in this study. This study was approved by institutional ethical review boards, and all patients provided written informed consent. Patients' baseline characteristics are summarized in Table 1.

The bone marrow samples were obtained during routine diagnostic procedure. Detailed protocols and sorting algorithms were published elsewhere $[17,18]$. Briefly, the PCs from MM patients in mononuclear cell fraction were enriched by antiCD138+ immunomagnetic beads and sorted using AutoMACS Pro (Miltenyi Biotec GmbH, Bergisch Gladbach, Germany). Purity of CD138+ fraction after magnetic cell sorting was measured by flow-cytometry. B-cells (CD19+) were sorted from CD138- fraction by fluorescence-activated cell sorting (FACS) using anti-CD19 fluorescence-labeled antibody (BD Biosciences, San Jose, CA, USA). Samples with $>80 \%$ plasma cells were used.

Interphase fluorescence in situ hybridization analysis (I-FISH). The I-FISH was performed on both B-cells and PCs testing for $I g H$ disruption at chromosome 14q32 using commercial probes XL IGH Break Apart Probe (MetaSystems $\mathrm{GmbH}$, Altlussheim, Germany) as a part of routine diagnostic procedure according to protocol previously described [19]. At least 100 cells were scored per sample; the threshold for $I g H$ disruption positivity was set to $20 \%$ according to standard procedure [20]. Digital image analysis was assessed by fluorescent microscope Olympus BX-61 equipped with a CCD Camera Vosskuhler 1300D and Lucia KARYO/FISH/CGH imaging system (Laboratory Imaging s.r.o., Prague, Czech Republic).

Array-comparative genomic hybridization (aCGH). Genomic DNA (gDNA) for aCGH experiments was extracted using commercially available kit (Puregene Core Kit A, Qiagen) according to manufacturer's protocol. Quality control of gDNA, digestion, labeling and hybridization steps were performed as previously described [21]. Briefly, $0.5 \mu \mathrm{g}$ of tumor and reference DNA were independently digested with Alu1 and Rsa1 (Promega, Madison, WI, USA) for 2 hours at 37C. Human
Table 1. Clinical and biological characteristics of the studied MM patients

\begin{tabular}{|c|c|}
\hline No. of patients & 54 \\
\hline Follow-up median (min-max) [months] & $19(1-185)$ \\
\hline Gender: males-females & $47.6 \%-52.4 \%$ \\
\hline Age median (range) [years] & $68(54-82)$ \\
\hline ISS stage: I-II-III & $38 \%-39 \%-23 \%$ \\
\hline Durie-Salmon stage: I-II-III & $16 \%-14 \%-70 \%$ \\
\hline Durie-Salmon substage: A-B & $74 \%-26 \%$ \\
\hline Igisotype: IgG-IgA-IgM-FLC & $67 \%-16 \%-5 \%-12 \%$ \\
\hline Light chains: kappa-lambda & $70 \%-30 \%$ \\
\hline \multicolumn{2}{|l|}{ No. of previous treatment lines } \\
\hline None (First line treatment) & $29(58 \%)$ \\
\hline One & $9(18 \%)$ \\
\hline Two & $4(8 \%)$ \\
\hline More (>2) & $8(16 \%)$ \\
\hline \multicolumn{2}{|l|}{ Treatment regimen } \\
\hline Bortezomib & $31(72 \%)$ \\
\hline Thalidomid & $2(5 \%)$ \\
\hline Lenalidomide & $10(23 \%)$ \\
\hline \multicolumn{2}{|l|}{ Biochemical parameter } \\
\hline Haemoglobin $(g / l)$ & $112(70.4-167)$ \\
\hline Thrombocytes (count x109) & $217(2.8-493)$ \\
\hline Calcium (mmol/l) & $2.34(1.85 .0-3.65)$ \\
\hline Albumin $(g / l)$ & $38.45(22.6-48.5)$ \\
\hline Creatinine (umol/l) & $92(49-932)$ \\
\hline$\beta 2$-microglobulin $(m g / l)$ & $3.42(1.3-30.2)$ \\
\hline Lactate dehydrogenase (ukat/l) & $3.49(1.77-8.49)$ \\
\hline$C$-reactive protein $(m g / l)$ & $3.9(0-111.5)$ \\
\hline Monoclonal $\operatorname{Ig}(g / l)$ & $28.3(0-85.6)$ \\
\hline Plasma cell infiltration of bone marrow (\%) & $35.7(0-94)$ \\
\hline
\end{tabular}

Genomic DNA: Female (Promega, Madison, WI, USA) was used as the normal reference in the hybridization experiments. Fluorescent labeling was made by BioPrime Total for Agilent Labeling Module (Invitrogen, Carlsbad, CA USA) with specific fluorescent dyes Alexa3 for reference and Alexa5 for tumor DNA. Labeled reactions were cleaned and hybridized at $65 \mathrm{C}$ for 40 hours. Agilent Human CGH 1x244K microarrays were scanned by Agilent Surescan scanner with $5 \mu \mathrm{m}$ resolution, features were extracted with Feature Extraction software and $\log 2$ ratio data were imported and analyzed by Agilent Genomic Workbench 7.0.4.0 (Agilent Technologies, Santa Clara, CA, USA). The copy number alterations were calculated using aberration detection module-2 (ADM-2) [22], using threeprobe and $0.2 \log 2$ filters, recommended default threshold 6 and accuracy of aberration calls confirmed on the basis of known FISH aberrations. To identify and eliminate common copy number variants, we used Database of Genomic Variants (http://www.openhelix.com/) for hg18. For the purpose of this study, only CNAs in gene and micro-RNA regions were considered in aberration list. Generated raw data of patients included in this study were deposited in the ArrayExpress 


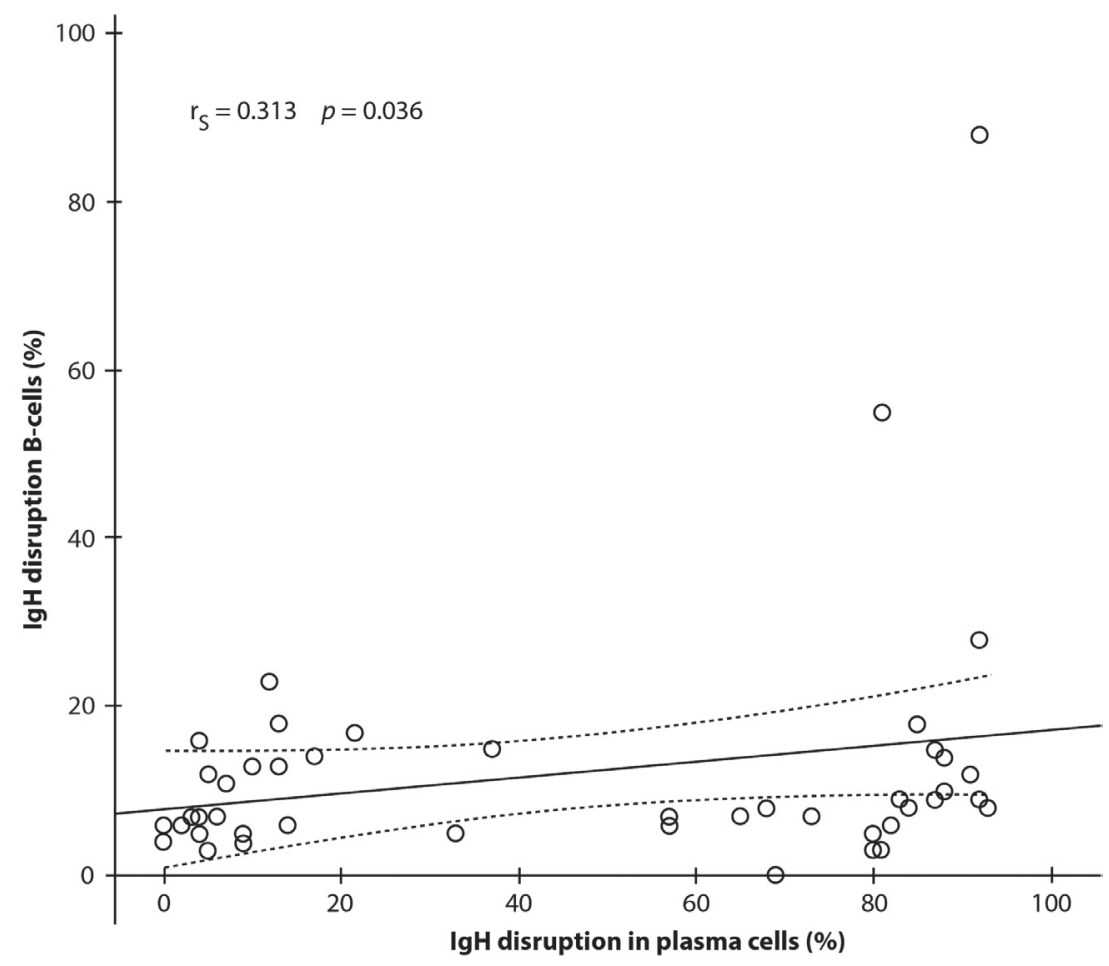

Figure 1. Correlation of percentage of $I g H$ locus rearrangements detected by I-FISH in B and plasma cell subpopulations obtained from same patient

Archive database under accession number E-MTAB-1401, available online (http://www.ebi.ac.uk/arrayexpress/).

Statistical analysis. Associations between chromosomal abnormalities are presented as Mean \pm Standard Deviation. Statistical analysis was performed using SPSS 20.0 (SPSS Inc., Chicago, IL, USA). Correlation was assessed using the Spearman correlation coefficient.

\section{Results}

I-FISH evaluation of IgH locus rearrangements in PCs and B-cells. To explore whether the proportion of IgH locus disruption B cell subpopulation correlates with occurrence of the $\mathrm{IgH}$ locus rearrangement in PCs, we analyzed samples obtained from $45 \mathrm{MM}$ patients with both samples (B-cells and PCs) available. Incidence of positive cases based on IgH disruption in PCs was observed in 57.8\% (26/45) cases, whereas it was $8.9 \%(4 / 45)$ cases in B-cell subpopulation. Interestingly, only $7 \%$ (3/45) of cases were double-positive based on evaluation of IgH locus disruption in B and PCs of MM patients (Table 2). Nevertheless, we found statistically significant correlation $(\mathrm{rS}=0.313 ; \mathrm{p}=0.036)$ between percentages of cells with $\mathrm{IgH}$ locus disruption detected in $\mathrm{B}$ and PCs subpopulations, obtained from the same patient (Figure 1).

The copy number alterations detected by aCGH in Bcells. The whole-genome screening by array CGH technique was performed on B-cell samples from $20 \mathrm{MM}$ patients. Over- all, CNAs were identified in $10 \%$ (2/20) of samples. In sample E14, we identified heterozygous deletion (of approximately $900 \mathrm{Kbp}$ ) in 13q14.3 affecting DLEU2, DLEU1, FAM10A4, DLEU7, RNASEH2B and miRNA genes miR-15 and miR-16 (Figure 2).

In contrast, we found complex genomic changes in patient E24. Gain of genetic material was found in chromosomes 1, 3 and X, whereas chromosomes 6 and 8 were affected with deletions. In chromosome 1, we found gain (1q) reaching from $1 \mathrm{q} 23$ to $1 \mathrm{q} 44$ with highly amplified, truncated region between 1q23.1 - 1q25.1. Three regions with CNAs were observed in chromosome 3. Amplification was observed in 3p14.1 - 3p11.1 (22.6 Mbp), 3q11.2 -3q13.31 (18.3 Mbp) and 3q26.2 - 3q26.31 (5.9 Mbp), respectively. The last region with gain of genetic material was found in chromosome X in Xq21.33 - Xqter. In chromosome 6 , we found $17 \mathrm{Mbp}$ region with heterozygous deletion in $6 \mathrm{p}$ reaching from $6 \mathrm{p} 23-6 \mathrm{p} 21.33$. Loss of approximately $2 / 3$ in $8 p$ reaching from 8 pter to $8 p 12$ was observed. Summary of genomic lesions in these two patients is shown in Table 3.

The copy number alterations detected by array-CGH in PCs. Both fractions (CD19+ and CD138+) for array-CGH analysis were available for 16 of $20 \mathrm{MM}$ patients. Using arrayCGH analyses on PC samples, we observed CNAs in 100\% (16/16) of cases. Overall, 254 CNAs (129 regions with gain and 125 with loss of genetic material) were found. Median of size was 15.7 Mbp for gains and 4.1 Mbp for deletions. Hyper- 
diploidy was found in $42.1 \%$ (8/19) with common presence of odd-numbered chromosomes 3, 5, 7, 9, 11, 15, 19 and 21 observed in $31.3 \%$ (5/16), $37.5 \%$ (6/16), $18,5 \%$ (3/16), $50 \%$ $(8 / 16), 37.5 \%(6 / 16), 50 \%(8 / 16), 43.8 \%(7 / 16)$ and $25 \%(4 / 16)$ of cases, respectively. Most common area of gain of genetic material (MRG) was a 5.6 Mbp region of duplication/amplification in region 1q21.2 - 1q22.3 observed in 50\% (8/16) of cases; gain of whole 1q was found in $31.3 \%(5 / 16)$ of cases. Frequent duplications were also observed in chromosome Xq. In $31.3 \%(5 / 16)$ of cases, we observed gain of genetic material in Xq26 - Xqter. The most common area of deletion was identified in chromosome 13, where we found a 19.4 Mbp region of loss of genetic material in 13q13.3 - 13q21.1, which was found in $43.8 \%$ (7/16) of cases. Moreover, incidence of monosomy 13 was observed in 25\% (4/16) of cases. Another CNA connected with loss of genetic material was monosomy $\mathrm{X}$, which was found in $37.5 \%$ (6/16) of cases. Further regions with heterozygous deletion were observed in $8 p(25 \% ; 4 / 16)$ and $16 \mathrm{q}(31.3 \% ; 5 / 16)$ regions. Interestingly, homozygous deletions were observed in $6.25 \%(1 / 16)$ of cases in loci carrying genes with important function in cycle in 12p13.1 (CDKN1B) or Nf- $\kappa \mathrm{B}$ in 11q22.1 (BIRC2, BIRC3) and 14q32.3 (TRAF3). Summary of CNAs in this cohort is shown in Figure 3.

\section{Discussion}

The role of premalignant clone of B-cells and their biological significance in multiple myeloma has been quite controversial. There are suggestions that cells phenotypically resembling mature B-cells and sharing immunoglobulin gene sequences and idiotype specificity with MM PCs can represent the premalignant clone or population with proliferative capacity for MM renewing [23-25].

After observing clonality evidence, it was sensible to expect these B-cells to mirror many genetic changes observed in the malignant PCs compartment. There are several studies investigating chromosomal abnormalities signature intrinsic for $\mathrm{PC}$ genome, and they are quite controversial. While one group showed that tumor-specific aneuploidy was not detected in the CD19+ bone marrow B-lymphoid cells from myeloma patients [26], another group identified a small number of CD19+ aneuploid lymphocytes (11\%) in BM and a small number of circulating CD19+ aneuploid lymphocytes (3\%) [9]. Finally, presence of hyperdiploid circulating CD19+ lymphocytes in $5-30 \%$ in MM patients was described [6]. Mentioned studies investigated detection of aneuploidy by flow-cytometry; FISH studies of chromosomal abnormalities in B-cells are also quite heterogeneous. Each kind of chromosomal change present in the myeloma tumor cells was found to be shared by a small fraction of CD19+ B-lymphocytes cells (0.1-1.8\%) [8].

We have applied a complex approach to genomic screening of BM B-lymphocytes (CD 19+) to study $\operatorname{IgH}$ locus rearrangements and DNA copy number changes inherent for MM cells.
Table 2. Frequency of $I g H$ locus rearrangements in total B-cell and plasma cell subpopulations.

\begin{tabular}{|c|c|c|}
\hline \multirow{2}{*}{ ID } & \multicolumn{2}{|c|}{ IgH disruption } \\
\hline & B-cells & Plasma cells \\
\hline $1-05-089$ & $23 \%$ & $12 \%$ \\
\hline MM-11-26 & $17 \%$ & $22 \%$ \\
\hline MM-11-27 & $16 \%$ & $4 \%$ \\
\hline MM-11-30 & $7 \%$ & $3 \%$ \\
\hline MM-11-34 & $6 \%$ & $2 \%$ \\
\hline MM-11-23 & $14 \%$ & $17 \%$ \\
\hline MM-11-40 & $3 \%$ & $80 \%$ \\
\hline MM-11-42 & $12 \%$ & $91 \%$ \\
\hline MM-11-45 & $6 \%$ & $0 \%$ \\
\hline MM-11-58 & $4 \%$ & $9 \%$ \\
\hline MM-11-56 & $5 \%$ & $9 \%$ \\
\hline MM-11-55 & $12 \%$ & $5 \%$ \\
\hline $1-03-040$ & $88 \%$ & $92 \%$ \\
\hline MM-11-60 & $7 \%$ & $4 \%$ \\
\hline MM-11-63 & $7 \%$ & $73 \%$ \\
\hline MM-11-70 & $10 \%$ & $88 \%$ \\
\hline MM-11-76 & $7 \%$ & $65 \%$ \\
\hline MM-11-78 & $4 \%$ & $0 \%$ \\
\hline MM-11-97 & $3 \%$ & $5 \%$ \\
\hline MM-11-93 & $28 \%$ & $92 \%$ \\
\hline MM-11-98 & $14 \%$ & $88 \%$ \\
\hline MM-11-128 & $15 \%$ & $37 \%$ \\
\hline MM-11-129 & $13 \%$ & $13 \%$ \\
\hline MM-11-130 & $13 \%$ & $10 \%$ \\
\hline MM-11-133 & $5 \%$ & $33 \%$ \\
\hline MM-11-138 & $7 \%$ & $6 \%$ \\
\hline MM-11-141 & $55 \%$ & $81 \%$ \\
\hline MM-11-143 & $15 \%$ & $87 \%$ \\
\hline MM-11-146 & $11 \%$ & $7 \%$ \\
\hline MM-11-160 & $9 \%$ & $92 \%$ \\
\hline MM-11-172 & $8 \%$ & $68 \%$ \\
\hline $1-03-054$ & $8 \%$ & $84 \%$ \\
\hline MM-11-175 & $8 \%$ & $93 \%$ \\
\hline MM-11-178 & $5 \%$ & $80 \%$ \\
\hline MM-11-182 & $0 \%$ & $69 \%$ \\
\hline MM-11-194 & $6 \%$ & $82 \%$ \\
\hline MM-11-200 & $9 \%$ & $83 \%$ \\
\hline MM-11-201 & $9 \%$ & $87 \%$ \\
\hline MM-11-226 & $18 \%$ & $13 \%$ \\
\hline MM-12-033 & $18 \%$ & $85 \%$ \\
\hline MM-12-046 & $6 \%$ & $14 \%$ \\
\hline MM-12-047 & $6 \%$ & $57 \%$ \\
\hline MM-12-050 & $7 \%$ & $57 \%$ \\
\hline MM-12-051 & $5 \%$ & $4 \%$ \\
\hline MM-12-052 & $3 \%$ & $81 \%$ \\
\hline
\end{tabular}

Bold - positive cases, according to positivity threshold 20\%.

Immunoglobulin heavy chain locus $(\mathrm{IgH})$ translocations at chromosome $14 \mathrm{q} 32-\mathrm{t}(14 \mathrm{q} 32)$ and several unbalanced chromosomal aberrations (e.g. del(13)(q14) or trisomies of chromosomes $3,5,7,9,11,15,19$ and 21) are considered to be 


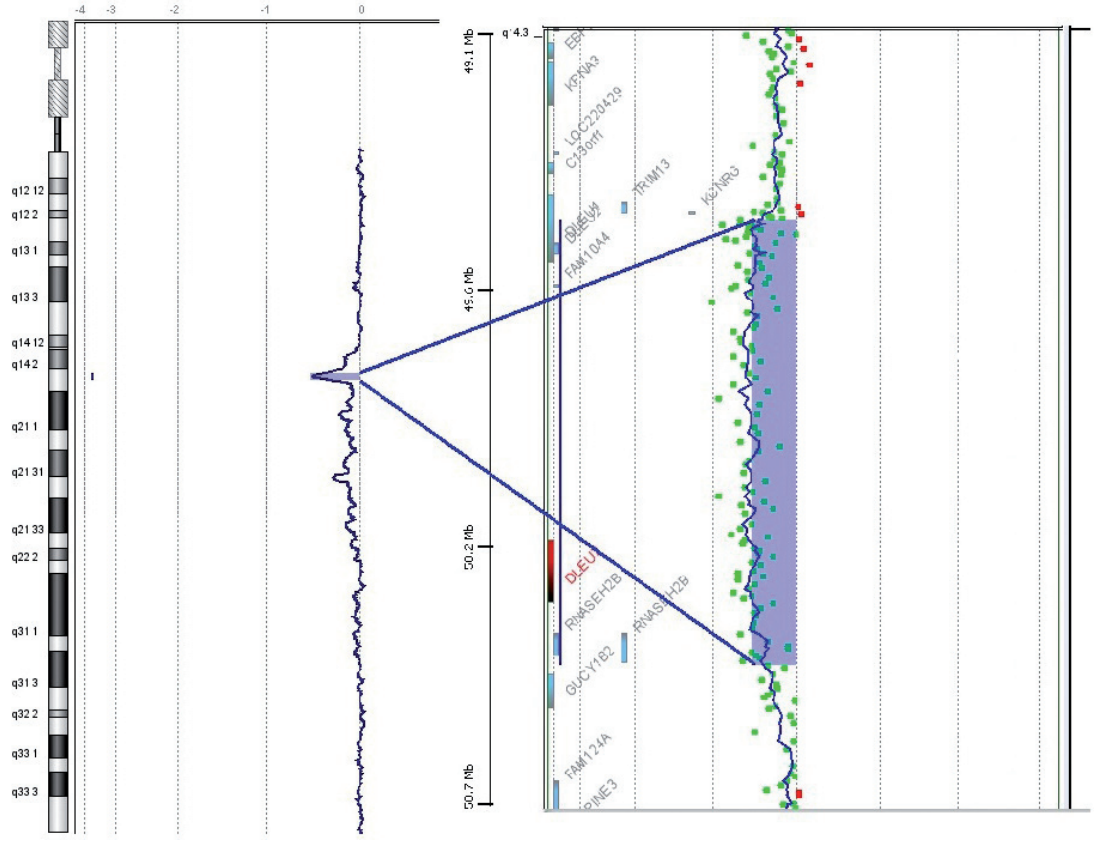

Figure 2. The profile of chromosome 13. Enlarged area shows heterozygous deletion affecting DLEU and Mir-15/16 genes cluster indicated by blue box in $13 q 14.3$ loci

early cytogenetic events in MM. The CD19 marker was chosen as a pan B-lymphocyte antigen that appears early in B-cell ontogeny and disappears with differentiation to PCs [27].

Analysis of $21 \mathrm{BM}$ B-cell samples from MM patients by array CGH technique revealed DNA copy number changes just in $10 \%(2 / 20)$ of cases in contrast to $100 \%(16 / 16)$ incidence of CNAs in PC samples.

Surprisingly, both cases displayed different genomic profile consistent with CLL in one case and MM in another. Deletions observed in case E14 affecting 13q14.3 loci carrying DLEU1, DLEU2 and DLEU7 are frequently found in B-cell chronic lymphocytic leukemia correlation with adverse prognosis [28]. Moreover, it was shown that deletion of microRNAs-15a/16-1 cluster could lead to more aggressive course of MM disease [29]. Similarly, complex karyotype and non-hyperdiploidy are common genetic features with negative impact on prognosis of MM patients. Particularly the incidence of gain in chromo- some 1q resulting in overexpression of CKS1B and ANPE 32 and therefore deregulation of Nf-kappaB pathway is associated with adverse prognosis for both newly diagnosed and relapsed MM patients [30,31].

The incidence of CNAs in our cohort is generally lower when compared to previous studies. This can be explained by technical limitations of aCGH sensitivity and expansiveness of a chosen population (CD19+), since any B-cell subpopulation carrying chromosomal abnormalities consisting of less than $30 \%$ will not be detectable. It can be consistent with previously mentioned FISH data of the Pilarski group because positivity cut-offs for unbalanced disruptions in their study were 4-13\% [32]. Nevertheless, the incidence of given changes in our two B-cell samples showed clear association with hematologic malignancies.

On the other hand, $I g H$ disruptions were detected in $8.9 \%$ (4/45) of investigated B cell from MM patients. Moreover,

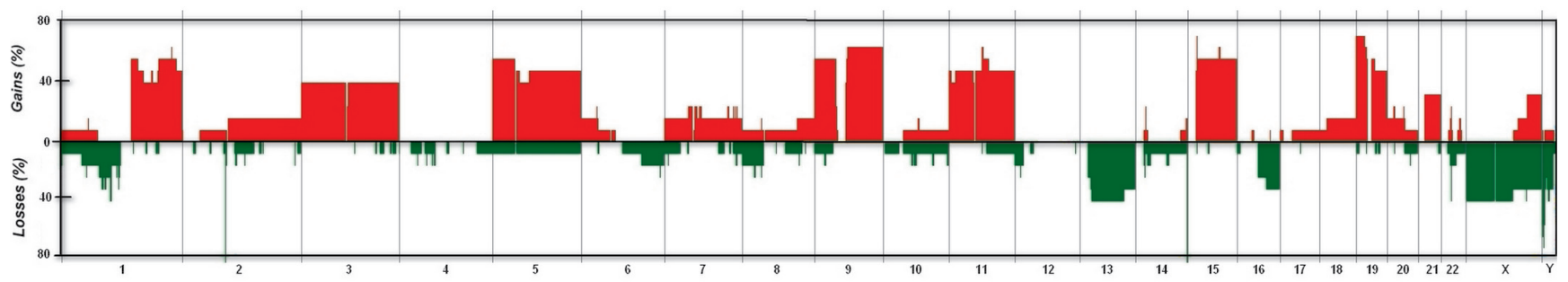

Figure 3. Graphical penetrance summary of copy number aberrations in cohort of 16 PCs samples using aCGH technique. Green color demonstrate the areas of deletions, red corresponds with regions with gain of genetic material (Output from Agilent Genomic Workbench 7.0.4.0) 
Table 3. Overview of DNA copy number alterations detected by array CGH in B-cell populations of 2 MM patients

\begin{tabular}{|c|c|c|c|c|c|c|c|c|}
\hline Sample & Chromosome & Aberration & Cytoband & Start & Stop & Size (Mbp) & Genes & miRNA \\
\hline E14 & 13 & loss & $13 q 14.3$ & 49506402 & 50449217 & 0,9 & $\begin{array}{l}\text { DLEU2, DLEU1, } \\
\text { FAM10A4, DLEU7, } \\
\text { RNASEH2B } \\
\end{array}$ & mir-16-1, hsa-mir-15a \\
\hline \multirow{7}{*}{ E24 } & 1 & gain & $q 23.1-q 44$ & 156847384 & $2,47 E+08$ & 90,3 & SPTA1 - PGBD2 & hsa-mir-1284, hsa-mir-1324 \\
\hline & 3 & gain & p14.1 - p11.1 & 67783354 & 90391757 & 22,6 & SUCLG2 - EHPA3 & hsa-mir-567 \\
\hline & 3 & gain & q11.2 - q13.31 & 96837353 & $1,15 \mathrm{E}+08$ & 18,4 & EPHA6 - KIAA1407 & hsa-mir-569 \\
\hline & 3 & gain & $q 26.2$ - q26.31 & 169781108 & $1,76 \mathrm{E}+08$ & 5,9 & $E V I 1-N L G N 1$ & hsa-mir-548a- 1 , hsa-mir-877 \\
\hline & 6 & loss & p23 - p21.33 & 14584134 & 31598761 & 17,0 & $J A R I D 2-M I C B$ & hsa-mir-596 - hsa-mir-548h \\
\hline & 8 & loss & p23.3-p12 & 391354 & 30029745 & 29,6 & FBXO25 - LOC286135 & hsa-mir-1237 - hsa-mir-612 \\
\hline & $\mathrm{x}$ & gain & $\mathrm{q} 21.33-\mathrm{q} 22.1$ & 96174622 & $1,55 \mathrm{E}+08$ & 58,4 & DIAPH2 - TMLHE & \\
\hline
\end{tabular}

significant correlation was revealed between positive B and PC samples in pair-wise MM samples analysis.

Above mentioned facts raise a question which parameters can be used as the basal criteria for abnormal B cell detection. If CD19+ B-lymphocytes are part of the myeloma clone, there should be evidence of myeloma specific genetic and phenotypic markers in this population. Probably IgH changes specific for MM cells happen in earlier steps of B-lineage development in process of MM cancerogenesis; however, cytogenetic abnormalities consisting of genetic markers for MM PC malignant clone are very rare in B-lymphocytes population and most of them are acquired by mature PCs.

Our data are consistent with a suggestion that the abundance of malignant B-cells has been vastly overestimated in the past and that they apparently represent a very rare population in myeloma. In the majority of myeloma patients, less than one out of 1000 peripheral blood or bone marrow mononuclear corresponds to a clonal B cell [7]. This assumption contradicts previously published estimates of up to two thirds of B-cells suggested to be clonal by detection of clonal $\mathrm{IgH}$ rearrangements by PCR $[33,34]$. We suggest that B-cells containing abnormal genome, which can refer to first malignant changes in possible precursor population of PC, consist possibly of a small percentage of BM B-cells (about 5\% of B-cells). These results are in agreement with a current US study [35]. Boucher et al. showed that BM CD19+ B-cells express a light chain identical to plasma cells and are therefore termed light chain restricted (LCR). The LCR B-cell mass was small in both newly diagnosed and relapsed patients $(\leq 1 \%)$.

Another discussible question is the role of abnormal B-cells in myeloma genesis. One hypothesis assumes that these cells are non-malignant remnants, which may have initially given rise to malignant plasma cell clone, but which do not have any significance in tumor maintenance [11]. It was suggested that this B cell subpopulation represents a compartment with stem cell like properties feeding the malignant PC compartment in multiple myeloma. Moreover, in vitro colony formation activ- ity for the mentioned LCR B-cell subset was observed [35]. It seems possible that abnormal B-cells may be involved in the human disease process; nevertheless, there is still no definite proof that B-cells represent the precursor tumor compartment with renewing capacity for MM cells.

Taken together, detection of genetic lesion in CD19+ Bcells provides another indirect genetic tool for estimation of the patient's prognosis. Introduction of novel techniques of whole-genome or exome sequencing may give insight into biology of abnormal B-cells with detection of causal mutations, which could have impact the transformation conditions of B-cells into malignant PCs. It also brings new insight into biology of MM in terms of characterization of genetic information of cells with possibly active role in cancerogenesis and pre-malignant stages of MM. However, further studies are needed in order to increase understanding of the role and effects of genetic changes of the B-cell populations in MM patients.

Acknowledgments: This study was supported by research grant MSM0021622434 from the Ministry of Education, Youth and Sports, Czech Republic and grant of The Czech Science Foundation GAP304/10/1395. Supported by Ministry of Health, Czech Republic - conceptual development of research organization (FNBr, 65269705) and by grants NS10207, NT11154, NT13190, NT12130 and NT13492 from the Internal Grant Agency of the Ministry of Health. The research leading to these results has received funding from the European Union Seventh Framework Program (FP7/2007-2013) under grant agreement nr 278570.

\section{References}

[1] KUEHL WM BP.Multiple myeloma: evolving genetic events and host interactions. Nat Rev Cancer 2002; 2: 175-178. http://dx.doi.org/10.1038/nrc746

[2] BRENNAN SK, MATSUI W Cancer stem cells: controversies in multiple myeloma. J Mol Med (Berl) 2009; 87: 1079-1085. http://dx.doi.org/10.1007/s00109-009-0531-7 
[3] BASAK GW, CARRIER E. The search for multiple myeloma stem cells: the long and winding road. Biol Blood Marrow Transplant. 2010; 16: 587-594. http://dx.doi.org/10.1016/ j.bbmt.2009.10.024

[4] HUFF CA, MATSUI W: Multiple myeloma cancer stem cells. Journal of clinical oncology : official journal of the American Society of Clinical Oncology 2008; 26: 2895-2900.

[5] GHOSH N, MATSUI W Cancer stem cells in multiple myeloma. Cancer letters 2009; 277: 1-7. http://dx.doi. org/10.1016/j.canlet.2008.08.005

[6] PILARSKI LM, MASELLIS-SMITH A, SZCZEPEK A, MANT MJ, BELCH AR et al. Circulating clonotypic B-cells in the biology of multiple myeloma: speculations on the origin of myeloma. Leuk Lymphoma 1996; 22: 375-383. http://dx.doi. org/10.3109/10428199609054775

[7] TREPEL M, MARTENS V, DOLL C, RAHLFF J, GOSCH B et al. Phenotypic detection of clonotypic B-cells in multiple myeloma by specific immunoglobulin ligands reveals their rarity in multiple myeloma. PLoS One 2012; 7: e31998. http://dx.doi. org/10.1371/journal.pone.0031998

[8] ZOJER N, SCHUSTER-KOLBE J, ASSMANN I, ACKERMANN J, STRASSER K et al. Chromosomal aberrations are shared by malignant plasma cells and a small fraction of circulating CD19+ cells in patients with myeloma and monoclonal gammopathy of undetermined significance. British journal of haematology 2002; 117: 852-859. http://dx.doi.org/10.1046/ j.1365-2141.2002.03529.x

[9] SANTONOCITO AM, CONSOLI U, BAGNATO S, MILONE G, PALUMBO GA et al. Flow cytometric detection of aneuploid CD38(++) plasmacells and CD19(+) B-lymphocytes in bone marrow, peripheral blood and PBSC harvest in multiple myeloma patients. Leuk Res 2004; 28: 469-477. http://dx.doi. org/10.1016/j.leukres.2003.09.015

[10] RASMUSSEN T, KUEHL M, LODAHL M, JOHNSEN HE, DAHL IM et al. Possible roles for activating RAS mutations in the MGUS to MM transition and in the intramedullary to extramedullary transition in some plasma cell tumors. Blood 2005; 105: 317-323. http://dx.doi.org/10.1182/blood-2004$\underline{03-0833}$

[11] PFEIFER S, PEREZ-ANDRES M, LUDWIG H, SAHOTA SS, ZOJER $\mathrm{N}$ et al. Evaluating the clonal hierarchy in light-chain multiple myeloma: implications against the myeloma stem cell hypothesis. Leukemia 2011; 25: 1213-1216. http://dx.doi. org/10.1038/leu.2011.70

[12] MASELLIS-SMITH A, BELCH AR, MANT MJ, TURLEY EA, PILARSKI LM et al. Hyaluronan-dependent motility of B-cells and leukemic plasma cells in blood, but not of bone marrow plasma cells, in multiple myeloma: Alternate use of receptor for hyaluronan-mediated motility (RHAMM) and CD44. Blood 1996; 87: 1891-1899

[13] PILARSKI LM, GIANNAKOPOULOS NV, SZCZEPEK AJ, MASELLIS AM, MANT MJ et al. In multiple myeloma, circulating hyperdiploid B-cells have clonotypic immunoglobulin heavy chain rearrangements and may mediate spread of disease. Clin Cancer Res 2000; 6: 585-596.

[14] REIMAN T, SEEBERGER K, TAYLOR BJ, SZCZEPEK AJ, HANSON J et al. Persistent preswitch clonotypic myeloma cells correlate with decreased survival: evidence for isotype switching within the myeloma clone. Blood 2001; 98: 27912799. http://dx.doi.org/10.1182/blood.V98.9.2791

[15] BILLADEAU D, AHMANN G, GREIPP P, VANNESS B. The Bone-Marrow of Multiple-Myeloma Patients Contains B-Cell Populations at Different Stages of Differentiation That Are Clonally Related to the Malignant Plasma-Cell. Journal of Experimental Medicine 1993; 178: 1023-1031. http://dx.doi. org/10.1084/jem.178.3.1023

[16] CORRADINI P, BOCCADORO M, VOENA C, PILERI A. Evidence for a Bone-Marrow B-Cell Transcribing Malignant Plasma-Cell Vdj Joined to C-Mu Sequence in Immunoglobulin (Igg)-Secreting and Iga-Secreting Multiple Myelomas. Journal of Experimental Medicine 1993; 178(3): 1091-1096. http://dx.doi.org/10.1084/jem.178.3.1091

[17] CUMOVA J, KOVAROVA L, POTACOVA A, BURESOVA I, KRYUKOV F et al. Optimization of immunomagnetic selection of myeloma cells from bone marrow using magnetic activated cell sorting. Int J Hematol 2010; 92: 314-319. http://dx.doi.org/10.1007/s12185-010-0651-4

[18] RAJA KR, KOVAROVA L, HAJEK R. Review of phenotypic markers used in flow cytometric analysis of MGUS and MM, and applicability of flow cytometry in other plasma cell disorders Br J Haematol. 2010; 149: 334-51. http://dx.doi. org/10.1111/j.1365-2141.2010.08121.x

[19] NEMEC P, ZEMANOVA Z, KUGLIK P, MICHALOVA K, TAJTLOVA J et al. Complex karyotype and translocation $\mathrm{t}(4$; 14) define patients with high-risk newly diagnosed multiple myeloma: results of CMG2002 trial. Leuk Lymphoma. 2012; 53: 920-7. http://dx.doi.org/10.3109/10428194.2011.634042

[20] ROSS FM, AVET-LOISEAU H, AMEYE G, GUTIERREZ NC, LIEBISCH P et al. Report from the European Myeloma Network on interphase FISH in multiple myeloma and related disorders. Haematologica 2012; 97: 1272-1277. http://dx.doi. org/10.3324/haematol.2011.056176

[21] SMETANA J, FROHLICH J, VRANOVA V, MIKULASOVA A, KUGLIK P et al. Oligonucleotide-based array CGH as a diagnostic tool in multiple myeloma patients. Klinicka onkologie 2011; 24 Suppl: S43-48.

[22] LIPSON D, AUMANN Y, BEN-DOR A, LINIAL N, YAKHINI Z: Efficient calculation of interval scores for DNA copy number data analysis. Journal of computational biology 2006; 13: 215-228. http://dx.doi.org/10.1089/cmb.2006.13.215

[23] BAKKUS MH, VAN RIET I, VAN CAMP B, THIELEMANS $\mathrm{K}$ Evidence that the clonogenic cell in multiple myeloma originates from a pre-switched but somatically mutated B cell. British Journal of Haematology 1994; 87: 68-74. http://dx.doi. org/10.1111/j.1365-2141.1994.tb04872.x

[24] BERENSON JR, VESCIO RA, HONG CH, CAO J, KIM A et al. Multiple myeloma clones are derived from a cell late in $\mathrm{B}$ lymphoid development. Current topics in microbiology and immunology 1995; 194: 25-33. http://dx.doi.org/10.1007/9783-642-79275-5 4

[25] RASMUSSEN T, KASTRUP J, KNUDSEN LM, JOHNSEN HE High numbers of clonal CD19+ cells in the peripheral blood of a patient with multiple myeloma. British Journal of Haematology 1999; 105: 265-267. 
[26] MCSWEENEY PA, WELLS DA, SHULTS KE, NASH RA, BENSINGER WI et al. Tumor-specific aneuploidy not detected in CD19+ B-lymphoid cells from myeloma patients in a multidimensional flow cytometric analysis. Blood 1996; 88: 622-632.

[27] TERSTAPPEN LW, JOHNSEN S, SEGERS-NOLTEN IM, LOKEN MR. Identification and characterization of plasma cells in normal human bone marrow by high-resolution flow cytometry. Blood 1990; 76: 1739-1747.

[28] EDELMANN J, HOLZMANN K, MILLER F, WINKLER D, BUHLER A et al. High-resolution genomic profiling of chronic lymphocytic leukemia reveals new recurrent genomic alterations. Blood. 2012 Dec 6; 120: 4783-94. Epub 2012 Oct 9 http://dx.doi.org/10.1182/blood-2012-04-423517

[29] GATT ME, ZHAO JJ, EBERT MS, ZHANG Y, CHU Z et al. MicroRNAs 15a/16-1 function as tumor suppressor genes in multiple myeloma. Blood. 2011; Jun 30; 117(26): 7188. Epub 2011 Apr 26. http://dx.doi.org/10.1182/blood-2011-04-348722

[30] ZHAN F, COLLA S, WU X, CHEN B, STEWART JP et al. CKS1B, overexpressed in aggressive disease, regulates multiple myeloma growth and survival through SKP2- and p27Kip1dependent and -independent mechanisms. Blood. 2007; 109: 4995-5001. http://dx.doi.org/10.1182/blood-2006-07-038703

[31] SMETANA J, BERANKOVA K, ZAORALOVA R, NEMEC P, GRESLIKOVA H et al. Gain(1)(q21) is an Unfavorable Genetic
Prognostic Factor for Patients With Relapsed Multiple Myeloma Treated With Thalidomide but Not for Those Treated With Bortezomib. Clin Lymphoma Myeloma Leuk. 2013 Jan 4.

[32] DEBES MARUN CS, BELCH AR, PILARSKI LM. In multiple myeloma, bone-marrow lymphocytes harboring the same chromosomal abnormalities as autologous plasma cells predict poor survival. Am J Hematol 2012; 87: 579-587. http://dx.doi. org/10.1002/ajh.23194

[33] SZCZEPEK AJ, SEEBERGER K, WIZNIAK J, MANT MJ, BELCH AR et al. A high frequency of circulating B-cells share clonotypic Ig heavy-chain VDJ rearrangements with autologous bone marrow plasma cells in multiple myeloma, as measured by single-cell and in situ reverse transcriptase polymerase chain reaction. Blood. 1998; 92: 2844-2855.

[34] TAYLOR BJ, PITTMAN JA, SEEBERGER K, MANT MJ, REIMAN $\mathrm{T}$ et al. Intraclonal homogeneity of clonotypic immunoglobulin $\mathrm{M}$ and diversity of nonclinical post-switch isotypes in multiple myeloma: insights into the evolution of the myeloma clone. Clin Cancer Res. 2002; 8: 502-513.

[35] BOUCHER K, PARQUET N, WIDEN R, SHAIN K, BAZ R et al. Stemness of B-cell progenitors in multiple myeloma bone marrow. Clin Cancer Res. 2012 Nov 15; 18(22): 6155-68. Epub 2012 Sep 17 http://dx.doi.org/10.1158/1078-0432.CCR-12$\underline{0531}$ 